\title{
Erratum to: Yttrium-90 Radioembolization \\ for Unresectable Combined Hepatocellular-Cholangiocarcinoma
}

\author{
Lauren S. Chan ${ }^{1} \cdot$ Daniel Y. Sze ${ }^{1} \cdot$ George A. Poultsides $^{2} \cdot$ John D. Louie $^{1} \cdot$ \\ Mohammed A. Abdelrazek Mohammed ${ }^{1} \cdot$ David S. Wang $^{1}$
}

Published online: 22 May 2017

(C) Springer Science+Business Media New York and the Cardiovascular and Interventional Radiological Society of Europe (CIRSE) 2017

\section{Erratum to: Cardiovasc Intervent Radiol DOI 10.1007/s00270-017-1648-7}

In the original article, Fig. 2B was incorrect. The correct version of Fig. $2 \mathrm{~B}$ is as follows:
The online version of the original article can be found under doi:10. 1007/s00270-017-1648-7.

\section{David S. Wang}

davidwang@stanford.edu

1 Division of Interventional Radiology, Stanford University School of Medicine, 300 Pasteur Drive, H3630, Stanford, CA 94305-5642, USA

2 Department of Surgery, Stanford University School of Medicine, Stanford, CA, USA

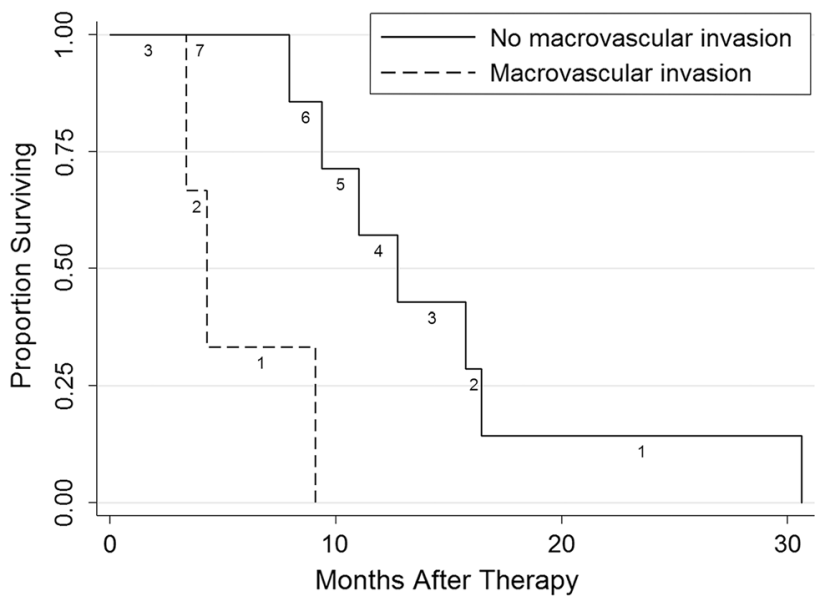

Fig. 2 Overall survival after radioembolization for cHCC-CC, A stratified by ECOG performance status $(P=0.032)$ and $\mathbf{B}$ by macrovascular invasion $(P=0.001)$ 